\title{
A familial chromosomal complex rearrangement confirms RUNX1T1 as a causative gene for intellectual disability and suggests that 1 p22.1p21.3 duplication is likely benign
}

\author{
Fabrizia Restaldi", Viola Alesi, Angela Aquilani, Silvia Genovese, Serena Russo, Valentina Coletti, Daniele Pompili, \\ Roberto Falasca, Bruno Dallapiccola, Rossella Capolino, Matteo Luciani and Antonio Novelli
}

\begin{abstract}
Background: Complex chromosomal rearrangements are constitutive structural aberrations involving three or more breaks. They can be balanced or unbalanced and result in different outcomes, depending on deletion/duplication of genomic material, gene disruption, or position effects.

Case presentation: We report on a patient presenting with severe anemia, splenomegaly, mild intellectual disability and facial dysmorphisms harboring a $4.3 \mathrm{Mb}$ duplication at 1p22.1p21.3 and a $2.1 \mathrm{Mb}$ deletion at 8q21.3q22.1, involving RUNX1T1 gene. The healthy brother presented the same duplication of chromosome $1 p$ as at 1 p22.1p21.3.

Conclusions: The rearrangement found both these siblings resulted from malsegregation in the proband and recombination in her healthy brother of a balanced paternal complex chromosomal rearrangement. These results confirm RUNX1T1 as a causative gene for intellectual disability and suggest the 1p22.1p21.3 duplication is likely benign.
\end{abstract}

Keywords: Complex chromosomal rearrangements, RUNX1T1, 1p22.1p21.3 duplication, 8q21.3q22.1 deletion

\section{Introduction}

Complex chromosomal rearrangements (CCRs) are constitutive structural aberrations, which involve three or more chromosomal breaks resulting in exchanges of genetic material. They are rare in human population [1], with an estimated $0.5 \%$ occurrence in newborns [2]. They are classified into three groups, basing on rearrangement type and breakpoints number [3]: 1 . Three-way exchange with three breaks in three different chromosomes, the most common type of CCRs; they are usually familial and transmitted by the mother. 2. Double two-way exchange with a coincidence of two separate simple reciprocal translocations, often described as double or multiple rearrangements. 3 . Exceptional CCRs associated with a more complicated rearrangement; they are mostly de novo and commonly associated with an abnormal phenotype. When unbalanced,

\footnotetext{
* Correspondence: fabrizia.restaldi@opbg.net
}

Bambino Gesù Children's Hospital, Rome, Italy they can result in abnormal phenotypes, depending on size and gene content of the affected regions. Also balanced CCR can result in a clinical phenotype as a consequence of gene disruption at the breakpoint or position effect of genes flanking the rearranged regions. Balanced CCRs can also undergo malsegregation during meiotic division, leading to unbalanced derivative chromosomes and affected offspring [4].

In the present study, we report on a patient presenting with severe anemia, splenomegaly, mild intellectual disability and facial dysmorphisms and harboring a double imbalance resulting from malsegregation of a paternal CCR. We also report on her brother presenting with mild facial dysmorphic features, who harbored a different chromosomal rearrangement due to a meiotic recombination of a paternal CCR. Genotype-phenotype association and published data argue for a pathological role for RUNX1T1 gene

(c) The Author(s). 2019 Open Access This article is distributed under the terms of the Creative Commons Attribution 4.0 International License (http://creativecommons.org/licenses/by/4.0/), which permits unrestricted use, distribution, and reproduction in any medium, provided you give appropriate credit to the original author(s) and the source, provide a link to the Creative Commons license, and indicate if changes were made. The Creative Commons Public Domain Dedication waiver (http://creativecommons.org/publicdomain/zero/1.0/) applies to the data made available in this article, unless otherwise stated. 


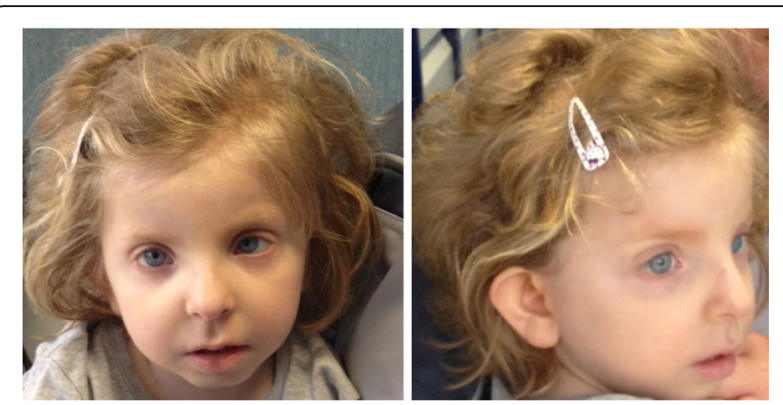

Fig. 1 Patient at 3 years old. Note dysmorphic facial features (blepharophimosis, ocular hypertelorism, long philtrum and abnormal ear configuration

imbalance, which can be regarded as an interesting candidate gene for intellectual disability.

\section{Case report}

We report on a patient already described by Valli R. et al. [5] providing further data missing in the previous report. In fact, locus specific FISH analysis of patient and firstdegree relatives allowed elucidating both familial reproductive risk and genotype-phenotype association.

This 9 year-old girl, child of non-consanguineous healthy parents, was born at term, with pre- and postnatal growth retardation, a surgically resolved atrial septal defect, dysmorphic facial features including blepharophimosis, ocular hypertelorism, long philtrum and abnormal ear configuration (Fig. 1), severe anemia and seizures. Metabolic diseases were excluded.

Because of persistent severe anemia and distinct clinical features a bone marrow biopsy was carried out which revealed unremarkable morphology of hematopoietic cells but confirmed erythroid hypo-cellularity. Standard karyotype analysis from peripheral blood was normal and FISH analysis searching for chromosome 7 monosomy or chromosome 8 trisomy on bone marrow cells tested negative. Fanconi Anemia and Blackfan Diamond Anaemia were excluded by means of Diepoxybutane (DEB) and genetic test respectively. Electroencephalogram and magnetic resonance imaging did not detect any abnormality.

\section{Material and methods}

Array-comparative genomic hybridization (array-CGH)

Patient's DNA was isolated from bone marrow and buccal swab, using QIAamp DNA mini kit (Qiagen). Array-CGH was performed on both samples in accordance with manufacturer's instructions, using Agilent Human CGH Microarray $60 \mathrm{~K}$ Kit (Agilent Technologies Array-CGH Kits, Santa Clara, CA). Images were obtained by Agilent scanner (G2505C) and data were extracted by Feature Extraction software (v.10.7.3.1). A graphical overview of the results was obtained using Agilent Genomic Workbench 7.0.4. Copy number variations $(\mathrm{CNVs})$ were identified with the ADM2 (Aberration Detection Method) algorithm and filtered consulting the Database of Genomic Variants

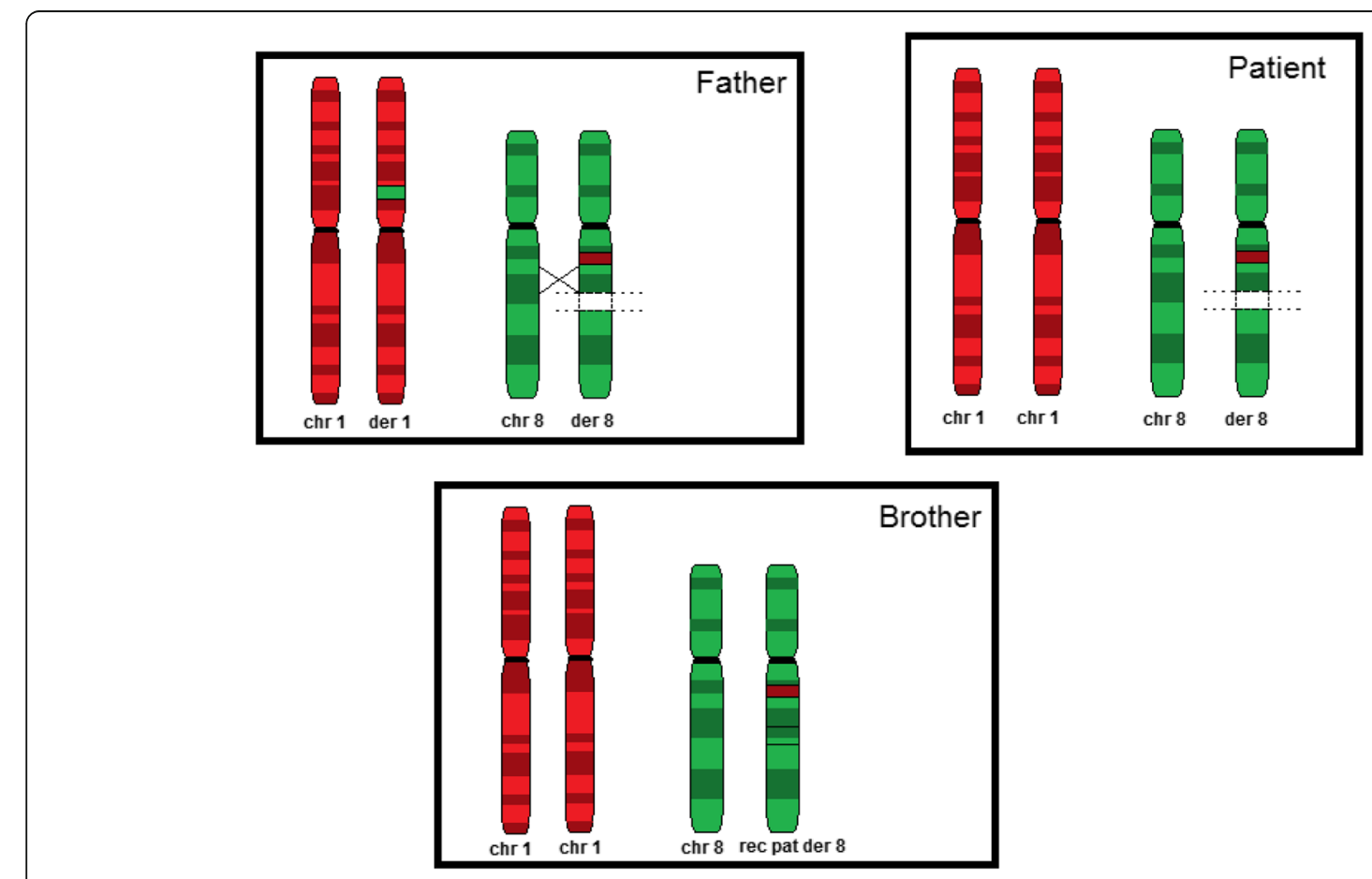

Fig. 2 segregation analysis 
[http://dgv.tcag.ca/dgv/app/home] and UCSC Database [https://genome.ucsc.edu/].

\section{Fluorescent in situ hybridization}

FISH (Fluorescent In Situ Hybridization) was performed on metaphase chromosome preparations of the patient,herparents, her brothers and her paternal grandparents.. The rearrangements revealed by array $\mathrm{CGH}$ were confirmed using different locus-specific BAC (Bacterial Artificial Chromosome) probes [RP11-731D23 [hg19] (93016930_93252167) at 8q21.3, RP11-4I24 [hg19](96024972_96164159) at1p21.3, RP11-545A9 [hg19] (92832705_93029934) at 1p22.1]. The BAC clones were selected from the University of California Santa Cruz (UCSC) genome browser (http://genome.ucsc. edu). FISH slides were analyzed with an Eclipse 80i (Nikon Instruments Europe B.V.), and images were captured using Genikon software (Nikon Instruments S.p.A.)

Whole exome-sequencing (WES) WES analysis was performed on patient's DNA, isolated from bone marrow sample. Library preparation and whole exome capture was performed by using the high-throughput NimbleGen SeqCap Exome Enrichment kit (Roche https://www.roche. $\mathrm{com} /$ ), according to the manufacture's protocol, and sequenced on an Illumina NextSeq 550 platform. The BaseSpace pipeline (Illumina, https://basespace.illumina.com/) and the VariantStudio software (Illumina, http://variantstudio.software.illumina.com/) were used for the variant calling and annotating variants, respectively. Sequencing data were aligned to the hg19 human reference genome.

\section{Results}

\section{Array-comparative genomic hybridization (array-CGH)} array CGH analysis performed on DNA from bone marrow and buccal swab detected a duplication, $4.3 \mathrm{Mb}$ in size, of the short arm of chromosome 1, at 1p22.1p21.3 region, and a deletion, $2.1 \mathrm{Mb}$ in size, on the long arm of chromosome 8, at 8q21.3q22.1,: arr [GRCh37]1p22.1p21.3(92122248_ $96403391) \times 3,8 q 21.3 q 22.1\left(92243681 \_94298184\right) \times 1$.

\section{FISH analysis}

In order to confirm the result and to evaluate parental segregation, FISH analysis was first carried out on patient's and her parents' metaphases. The father presented a balanced CCR, consisting of two insertions on chromosomes 1 and 8 . In detail, the $1 \mathrm{p} 22.1 \mathrm{p} 21$ region was translocated onto the long arm of a chromosome 8 , approximately at 8q12, while a different segment of the same chromosome 8 , 8q21.3q22.1, was inserted onto the short arm of the rearranged chromosome 1 (1p22.1) [ish ins $(1 ; 8)(\mathrm{p} 22.1 ; \mathrm{q} 21.3 \mathrm{q} 2$ 2.1)(RP11-4I24-,RP11-731D23+;RP11-4I24+,RP11-731D23),ins (8;1)(q12;p22.1p21.3)(RP11-4I24+,RP11-731D23-;RP11 -4I24-,RP11-731D23+)].

The proband inherited from her father a normal chromosome 1 and the derivative chromosome 8 , resulting in 1p22.1p21.3 duplication and 8q21.3q22.1 deletion (Fig. 2) [ish der(8) ins (8;1)(q12;p22.1p21.3) ins (1;8)(p22.1;q21.3q2 2.1) pat (RP11-4I42+,RP11-731D23-)].

Considering the paternal origin of the $\operatorname{der}(8)$ chromosome, FISH analysis was then performed on the patient's two brothers and paternal grandparents. The patient's elder brother presented a rearranged der(8), different form the one found in his sister, harboring the sole $1 \mathrm{p} 22.1 \mathrm{p} 21.3$
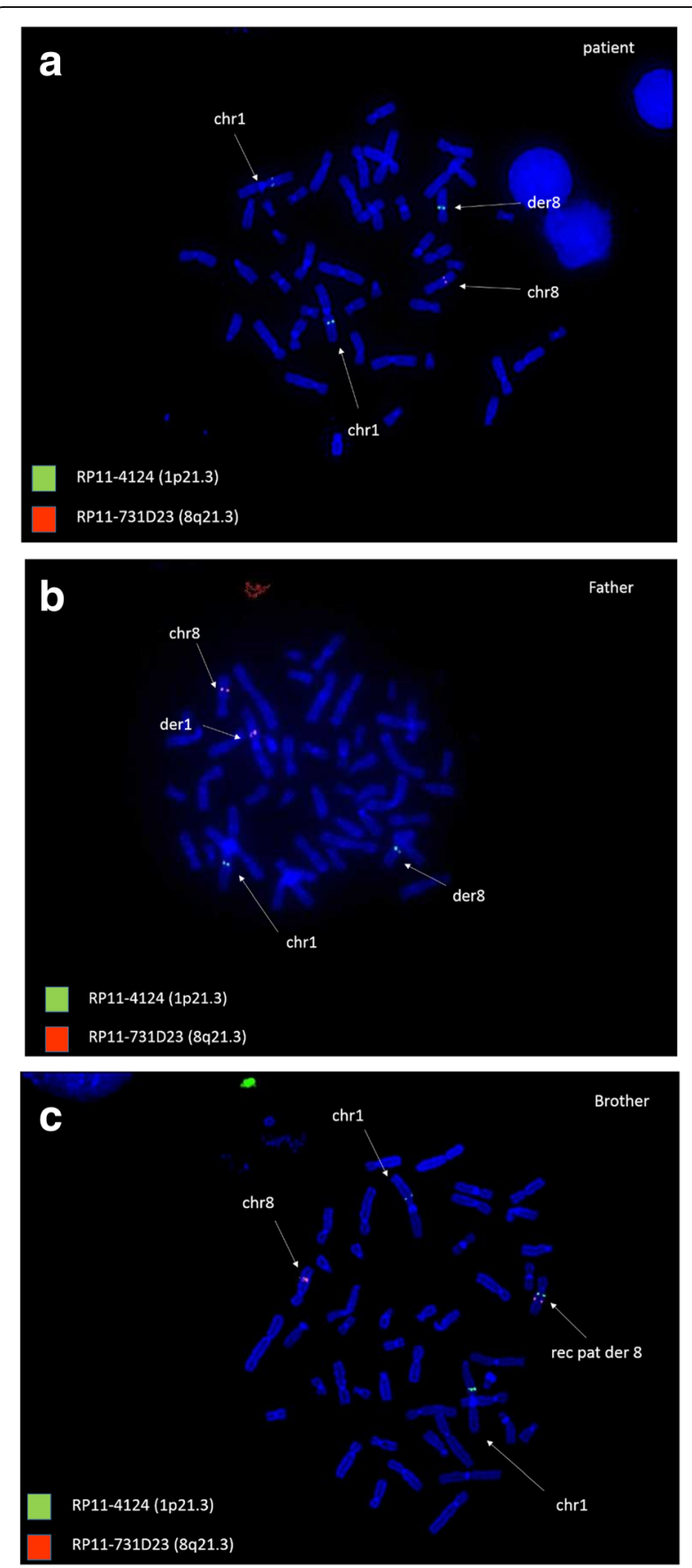

Fig. 3 FISH analysis of metaphases from patient (a), her father (b) and her brother (c) 
duplication [ish rec (8) ins $(8 ; 1)(\mathrm{q} 12 ; \mathrm{p} 22.1 \mathrm{p} 21.3)$ pat (RP1 1-4I24+,RP11-731D23+)]. A crossing-over between the $\operatorname{der}(8)$ and the normal chromosome 8 in the paternal meiosis, had restored the missing 8q21.3q22.1 from the normal homologous to the newly derived chromosome 8 (Figs. 2 and 3). FISH analysis tested normal on the other analyzed subjects.

Whole exome-sequencing (WES) analysisAccording to myeloid phenotype of our patient, WES analysis was performed on patient's DNA extracted from bone marrow in order to exclude a hemizygous sequence variant in RUNX1T1 gene (8q21.3) acting as a second hit. No variants were detected on RUNX1T1 coding regions, considering a mosaicism detection threshold higher than $10 \%$.

\section{Discussion}

We report a young girl, presenting with growth retardation, surgically resolved atrial septal defect, macrocytic anemia and mild cognitive impairment with learning disability and harboring a double genomic imbalance. The rearrangement arose from malsegregation of a 5-breakpoints paternal complex rearrangement, involving chromosome 1 and 8 (Fig. 2), which resulted in a $4.3 \mathrm{Mb}$ duplication at $1 \mathrm{p} 22.1 \mathrm{p} 21.3$ and in a $2.1 \mathrm{Mb}$ deletion at $8 \mathrm{q} 21.3 \mathrm{q} 22.1$. The 1p22.1p21.3 duplication, involved 52 UCSC genes, including 8 reported as OMIM Disease Causing (BRDT, GLML, GFI1, RPL5, GCLM, ABCA4, ABCD3, ALG14). No other overlapping cases of $1 \mathrm{p} 22.1 \mathrm{p} 21.3$ duplications have been described in literature so far and, as this duplication is not reported as benign in CNV reference databases (DGV, Database of genomic variants), it was classified as VoUS (Variant of Unknown Significance). However, despite its extension and gene content, it is unlikely that this duplicatioin had a consistent effect on the patient's phenotype since the 10-year old carrier brother displayed an adequate cognitive and behavioral profile. The 8q21.3q22.1 deletion involved three protein coding genes (SLC26A7, RUNX1T1, TRIQK), none of which described as OMIM Disease Causing. Several patients with deletions encompassing this region were described, mostly aiming to molecularly define the Nablus Mask-Like syndrome (NMLS), a disorder characterized by distinct facial features, including tight, glistening facial skin, blepharophimosis, ocular hypertelorism, abnormal ear architecture, sparse eyebrows and upswept frontal hairline. A smaller region of overlap among affected subject suggested a $1.84 \mathrm{Mb}$ critical region at $8 \mathrm{q} 22.1$, from 94.43 to $96.27 \mathrm{Mb}$ [6]. This region, considered necessary but not sufficient for the phenotype presentation, lies downstream our patient's deletion, with no overlap [7].

Only four cases harboring smaller and proximal deletions have been reported far [7, 8, DECIPHER 265010, $287,719]$. They presented with mild intellectual disability, learning and speech delay and, in two cases, heart defects (Table 1). Interestingly, the deletion described by Huynh et al.[8] only involved RUNX1T1, which was considered an interesting candidate gene for intellectual disability. The authors referred to a previously reported case by Zhang et al. [9], in which a balanced translocation t $(5 ; 8)(\mathrm{q} 31 ; \mathrm{q} 21)$ caused RUNX1T1 inactivation in a patient presenting with mild intellectual disability, ventricular septal defect and facial dysmorphic features. RUNX1T1 is a member of the myeloid translocation gene family. It interacts with DNA-bound transcription factors and histone-modifying enzymes, having a role in transcriptional repression. RUNX1T1 is expressed in several human tissues, in particular brain and heart, suggesting that its haploinsufficiency can be associated with mild intellectual disability and heart defects $[8,9]$.

The macrocytic anemia presented in our patient has not been associated previously with $8 \mathrm{q}$ deletion. Valli et al. [5] reported in short the present patient focusing on RUNX1T1 as a potential causative gene for the

Table 1 Patients harboring 8q21.3 proximal deletion < $4 \mathrm{Mb}$ and encompassing RUNX1T1

\begin{tabular}{|c|c|c|c|c|}
\hline ID & reported phenotype & array-CGH results [hg19] & size & protein coding genes \\
\hline $\begin{array}{l}\text { Allanson 2012, } \\
\text { pt. } 6 \text { (DECIPHER 2399) }\end{array}$ & $\begin{array}{l}\text { short stature, speech an learning delay, } \\
\text { Intellectual disability, prominent nasal } \\
\text { bridge, mild pulmonary valve stenosis, } \\
\text { minor facial anomalies }\end{array}$ & $\begin{array}{l}8 q 21.3 q 22.1(91,953,214- \\
95,550,581) \times 1\end{array}$ & $3.4 \mathrm{Mb}$ & $\begin{array}{l}\text { NECAB1, C8orf88, TMEM55A, OTUD6B, } \\
\text { LRRC69, SLC26A7, RUNX1T1, TRIQK, } \\
\text { FAM92A1, RBM12B, TMEM67, PDP1, } \\
\text { CDH17, GEM, RAD54B, FSBP, KIAA1429 }\end{array}$ \\
\hline Huynh 2012 & $\begin{array}{l}\text { mild intellectual disability, learnin disability, } \\
\text { short stature, minor facial anomalies }\end{array}$ & $\begin{array}{l}8 \mathrm{q} 21.3(93,010,222- \\
93,048,079) \times 1 \mathrm{dn}\end{array}$ & $38 \mathrm{~Kb}$ & RUNX1T1 partially involved \\
\hline DECIPHER 265010 & Intellectual disability & $\begin{array}{l}\text { 8q21.3q22.1 (93,045,661- } \\
93,317,115) \times 1 \text { inh from } \\
\text { a parent with a similar } \\
\text { phenotype }\end{array}$ & $271 \mathrm{~Kb}$ & RUNX1T1 partially involved \\
\hline DECIPHER 287719 & Intellectual disability & $\begin{array}{l}8 q 21.3 q 22.1(92,193,866- \\
94,430,363) \times 1\end{array}$ & $2.2 \mathrm{Mb}$ & LRRC69, SLC26A7, RUNX1T1, TRIQK \\
\hline our patient & $\begin{array}{l}\text { atrial septal defeact, mild short stature, } \\
\text { intellectual disability, speech and learning } \\
\text { delay, minor facial anomalies, severe } \\
\text { non-haemolitic anemia, sezure episodes }\end{array}$ & $\begin{array}{l}8 q 21.3 q 22.1(92,243,681- \\
94,298,184) \times 1\end{array}$ & $2.1 \mathrm{Mb}$ & SLC26A7, RUNX1T1, TRIQK \\
\hline
\end{tabular}


hematological findings. In fact, $\mathrm{t}(8,21)(\mathrm{q} 22 ; \mathrm{q} 22)$ translocation, resulting in a RUNX1-RUNX1T1 chimeric gene production, is one of the most frequent chromosomal abnormalities in acute myeloid leukemia. However, no evidence for an association between RUNX1T1 deletion and a myeloid phenotype has been documented so far. Considering its role as a corepressor factor, we evaluated the possible presence of a hemizygous point mutation in bone marrow tissue, following a classical two hits model. No variant was detected by direct sequencing (WES analysis), although low-level mosaicisms cannot been excluded by molecular techniques.

The expression of this complex phenotype may also be attributed to the concomitant presence of $1 \mathrm{p}$ duplication as a contributory cause. However, it is not possible to exclude that the patient's hematological disease results from an independent mechanism with unknown genetics or environmental etiological basis.

\section{Conclusion}

We report a familial chromosome rearrangement presenting with different outcomes: a father with a five breakpoints reciprocal insertion involving chromosomes 1 and 8 , and two children, a girl harboring a $1 \mathrm{p}$ duplication and an $8 \mathrm{q}$ deletion, and a boy presenting with 1p duplication. Genotype-phenotype analysis suggests RUNX1T1 as a causative gene for intellectual disability and proposes $1 \mathrm{p} 22.1 \mathrm{p} 21.3$ duplication as a benign imbalance.

\section{Abbreviations \\ ADM2: Aberration Detection Method; array-CGH: Array-Comparative Genomic Hybridization; BAC: Bacterial Artificial Chromosome; CCR: Complex chromosomal rearrangements; CNVs: Copy number variations; \\ DEB: Diepoxybutane; DECIPHER: Database of Chromosomal Imbalance and Phenotype in Humans using Ensembl Resources; DGV: Database of genomic variants; FISH: Fluorescent In Situ Hybridization; OMIM: Online Mendelian Inheritance in Man; UCSC: University of California at Santa Cruz; UCSC: University of California Santa Cruz; VoUS: Variant of unknown significance; WES: Whole exome-sequencing}

\section{Acknowledgements}

None.

\section{Authors' contributions}

$R F, A L, L M$ prepared the manuscript. $R F, A V, A A, G S, R S, C V, P D$ and $F R$ performed genetic testing and analyzed the results. $L M, A A$ and $C R$ provided medical care to the patient. DB and LF revised the manuscript. All authors provided revisions and feedback on the manuscript draft. All authors read and approved the final manuscript.

\section{Funding}

This research received no specific grant from any funding agency.

\section{Availability of data and materials}

Data sharing is not applicable to this article as no datasets were generated or analyzed during the current study.

\section{Consent for publication}

Informed consent for analysis was obtained from patient's parents and the study protocol conforms to the Italian ethical guidelines.

All participants gave written consent for the publication of the identifying photographs.

\section{Competing interests}

The authors declare that they have no competing interests.

Received: 25 February 2019 Accepted: 4 June 2019

Published online: 14 June 2019

\section{References}

1. Liao Y, Wang L, Zhang D, Liu C. Identification of a balanced complex chromosomal rearrangement involving chromosomes 3,18 and 21 with recurrent abortion: case report. Mol Cytogenet. 2014;7:39.

2. Durmaz CD, Yararbaş K, Kutlay NY, Türedi Ö, Akın I, Gürbüz C, Karataş G. Tükün. A Unusual Chromosomal Rearrangement Resulted in Interstitial Monosomy 9p: Case Report. Cytogenet Genome Res. 2016;148(1):19-24.

3. Gardner RJM, Sutherland GR, Lisa G. Shaffer, chromosome abnormalities and genetic counselling. UK: Oxford University Press; 2012.

4. Alesi V, Orlando V, Genovese S, Loddo S, Pisaneschi E, Pompili D, Surace C, Restaldi F, Digilio MC, Dallapiccola B, Dentici ML, Novelli A. Interstitial 10q21. 1q23.31 Duplication due to Meiotic Recombination of a Paternal Balanced Complex Rearrangement: Cytogenetic and Molecular Characterization. Cytogenet Genome Res. 2017;151(4):179-85.

5. Valli R, Vinti L, Frattini A, Fabbri M, Montalbano G, Olivieri C, Minelli A, Locatelli F, Pasquali F, Maserati E. Bone marrow failure may be caused by chromosome anomalies exerting effects on RUNX1T1 gene. Mol Cytogenet. 2018;11:2.

6. Overhoff J, Rabideau MM, Bird LM, Schweitzer DN, Haynes K, Schultz RA, Shaffer LG, Rosenfeld JA, Ellison JW. Refinement of the 8q22.1 microdeletion critical region associated with Nablus mask-like facial syndrome. Am J Med Genet A. 2014;164A(1):259-63.

7. Allanson J, Smith A, Hare H, Albrecht B, Bijlsma E, Dallapiccola B, Donti E, Fitzpatrick D, Isidor B, Lachlan K, Le Caignec C, Prontera P, Raas-Rothschild A, Rogaia D, van Bon B, Aradhya S, Crocker SF, Jarinova O, McGowan-Jordan J, Boycott K, Bulman D, Fagerberg CR. Nablus mask-like facial syndrome: deletion of chromosome 8q22.1 is necessary but not sufficient to cause the phenotype. Am J Med Genet A. 2012;158A(9):2091-9.

8. Huynh MT, Béri-Dexheimer M, Bonnet C, Bronner M, Khan AA, Allou L, Philippe C, Vigneron J, Jonveaux P. RUNX1T1, a chromatin repression protein, is a candidate gene for autosomal dominant intellectual disability. Am J Med Genet A. 2012;158A(7):1782-4.

9. Zhang L, Tümer Z, Møllgård K, Barbi G, Rossier E, Bendsen E, Møller RS, Ullmann R, He J, Papadopoulos N, Tommerup N, Larsen LA. Characterization of a t (5;8)(q31;q21) translocation in a patient with mental retardation and congenital heart disease: implications for involvement of RUNX1T1 in human brain and heart development. Eur J Hum Genet. 2009;17(8):1010-8.

\section{Publisher's Note}

Springer Nature remains neutral with regard to jurisdictional claims in published maps and institutional affiliations.
Ready to submit your research? Choose BMC and benefit from:
- fast, convenient online submission
- thorough peer review by experienced researchers in your field
- rapid publication on acceptance
- support for research data, including large and complex data types
- gold Open Access which fosters wider collaboration and increased citations
- maximum visibility for your research: over $100 \mathrm{M}$ website views per year
At BMC, research is always in progress.
Learn more biomedcentral.com/submissions 